\title{
A comparative investigation of the corrosion and tribocorrosion behaviour of nitrocarburized, gas nitrided, fluidized-bed nitrided, and plasma nitrided plastic mould steel
}

\author{
E. Boztepe ${ }^{\mathrm{a}}$, A.C. Alves ${ }^{\mathrm{b}, *}$, E. Ariza ${ }^{\mathrm{b}, \mathrm{c}}$, L.A. Rocha, ${ }^{\mathrm{b}, \mathrm{d}, \mathrm{e}}$, N. Cansever ${ }^{\mathrm{a}}$, F. Toptan ${ }^{\mathrm{b}, \mathrm{e}, \mathrm{f}}$ \\ ${ }^{a}$ Yildiz Technical University, Department of Metallurgical and Materials Engineering, Faculty of Chemistry \& Metallurgy, Davutpasa Campus, 34210 Esenler, Istanbul, \\ Turkey

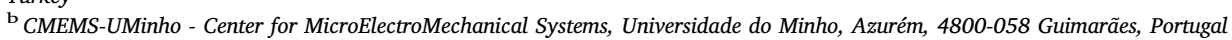 \\ c Universidade do Minho, SEMAT/UM, Azurém, 4800-058 Guimarães, Portugal \\ d UNESP_Univ. Estadual Paulista, Faculdade de Ciências de Bauru, Dep. Física, 17033-360 Bauru, SP, Brazil \\ e IBTN/Br - Brazilan Branch of the Institute of Biomaterials, Tribocorrosion and Nanomedicine, Bauru, SP, Brazil \\ ${ }^{\mathrm{f}}$ Universidade do Minho, Dept. Eng. Mecânica, Azurém, 4800-058 Guimarães, Portugal
}

\section{A R T I C L E I N F O}

\section{Keywords:}

Corrosion

Nitriding

Nitrocarburising

Plastic mould steel

Tribocorrosion

\begin{abstract}
A B S T R A C T
The present study aims to compare the corrosion and tribocorrosion behaviour of nitrocarburized, gas-nitrided, fluidized-bed nitrided, and plasma-nitrided Impax Supreme (equivalent to AISI P20) pre-hardened plastic mould steel. Corrosion behaviour was investigated by electrochemical impedance spectroscopy and potentiodynamic polarization in $3.5 \mathrm{wt} \% \mathrm{NaCl}$ solution. Tribocorrosion tests were performed in the same solution under open circuit potential during sliding against $10 \mathrm{~mm}$ alumina balls. Results showed that plasma-nitrided samples presented better corrosion behaviour in terms of tendency to corrosion, corrosion rate, and polarization resistance, as compared to the other studied surface treatments. Together with nitrocarburised samples, plasmanitrided samples also exhibited lower tendency to corrosion under sliding.
\end{abstract}

\section{Introduction}

Engineering plastics are an important class of consumer products wherein the continuous growth of the market requires low-cost but high performance plastic mould steels having high wear and corrosion resistance $[1,2]$. Nitriding is a common surface treatment technique where introduction of nitrogen results in improved mechanical properties together with higher wear and corrosion resistance $[2,3]$.

Several commercial nitriding systems are available achieving the introduction of nitrogen in liquid, controlled gas or plasma environments [4]. Gas nitriding (GN) process is performed by introducing nitrogen into a steel surface at the temperatures ranging between $495{ }^{\circ} \mathrm{C}$ and $565^{\circ} \mathrm{C}$ whereas fluidized bed nitriding (FBN) process is performed in a fluidized bed furnace, usually under ammonia gas $[5,6]$. In plasma (or ion) nitriding (PN), high-voltage electrical energy is used to form plasma in vacuum, where nitrogen can diffuse into the surface after a glow discharge with the steel in a gas mixture of $\mathrm{H}_{2}$ and $\mathrm{N}_{2}$ [5,7]. In nitrocarburizing (NC) process, in addition to the diffusion of nitrogen, diffusion of carbon also occurs which is usually carried out at temperatures between 560 and $580{ }^{\circ} \mathrm{C}$ [8]. Within these processes PN is gaining more attention particularly due to the environmental concerns [4].

Nitriding $[7,9-11]$ or nitrocarburizing $[8,12]$ process results in two layers on the surface, namely a relatively thicker diffusion layer and a thin, multiphase outmost structure called compound (or white) layer. The diffusion layer mainly consists of interstitial atoms in solid solution and if the solubility limit is reached, it also contains coherent nitride precipitates. The compound layer, on the other hand, contains $\varepsilon$ $\left(\mathrm{Fe}_{2-3} \mathrm{~N}\right)$ and $\gamma^{\prime}\left(\mathrm{Fe}_{4} \mathrm{~N}\right)$, as well as other nitrides formed with alloying elements $[2,3,9,13,14]$. In general, the diffusion layer determines the strength whereas the compound layer determines the tribological and corrosion behaviour [2,9,12].

Individual corrosion and wear data are commonly reported for the plastic injection mould materials. It has been reported that acids and chlorides formed due to the decomposition of thermoplastics by overheating can create a corrosive environment [1]. Furthermore, during the injection moulding process, liberated gases from plastic materials at elevated temperatures can cause localized corrosion on the mould

\footnotetext{
*Corresponding author at: CMEMS-UMinho - Center for MicroElectroMechanical Systems, Universidade do Minho, Departamento de Engenharia Mecânica, Azurém, 4800-058 Guimarães, Portugal.

E-mail address: alexandra@dem.uminho.pt (A.C. Alves).
} 
material [15]. On the other hand, plastic injection moulds suffer mechanical wear due to the relative movements of the mould parts, as well as due to the abrasive actions exerted by the reinforcement materials such as hard and abrasive fibres or whiskers [15-18].

It is well-known that nitriding improves wear and corrosion behaviour of steel surfaces [19-23]. A large number of studies are available in the literature focusing on either wear or corrosion behaviour of nitrided surfaces. On the other hand, some authors performed both wear and corrosion studies on the same surfaces, but applied individual wear and corrosion tests. Within these studies, Novak et al. [3] studied the influence of plasma-nitriding conditions on the abrasive wear and corrosion resistance of the niobium-alloyed PM tool steel by wear tests using a modified pin-on-disc tribometer, and corrosion tests in $0.6 \mathrm{wt} \%$ $\mathrm{NaCl}$. The authors reported that wear resistance was depended on the surface hardness and roughness, microstructure, and phase composition of layers whereas corrosion resistance was mainly affected by the presence of a compound layer due to its behaviour as a barrier against corrosive attack, thus, as the thickness of the layer was increased, corrosion resistance increased. Wen [2] studied the wear and corrosion behaviour of the plasma nitrided plastic mould steel (NAK55) by dry sliding wear tests using a block-on-ring wear tester, and corrosion tests by anodic polarization in $3.5 \mathrm{wt} \% \mathrm{NaCl}$ solution. The author reported reduced wear and coefficient of friction (COF) for the plasma nitrided samples where wear resistance was related to the increase in the thickness of the diffusion layer. Besides, higher corrosion potentials and lower corrosion rates were reported for the plasma nitrided samples. Esfandiari and Dong [24] studied the wear behaviour of plasma nitrided A286 precipitation-hardening stainless steel by using a pin-ondisc tribometer under both dry sliding condition and in a $3.5 \mathrm{wt} \% \mathrm{NaCl}$ solution but without measuring the electrochemical response under sliding. The authors reported 600 times lower wear loss volume for dry conditions and 30 times lower wear loss volume in the $\mathrm{NaCl}$ solution.

In their service conditions, nitrided plastic mould steels suffer corrosion and wear, simultaneously. But as shown, most of the literature evaluate the corrosion and wear behaviour by individual corrosion and wear tests, or just in some cases, wear tests in wet conditions. However, it is known that when the corrosion and wear occur simultaneously (i.e. tribocorrosion), the total degradation rate is usually different than the sum of the corrosion rate and the wear rate measured individually [25]. Although most of the applications of the nitrided steels are subjected to corrosion and wear simultaneously (e.g. plastic mould steels), to the best of our knowledge, there is no reported study comparing the tribocorrosion behaviour between different nitrided surfaces. Thus, the novel aim of this study was to compare the behaviour of Impax Supreme (equivalent to AISI P20) premium pre-hardened plastic mould steel after commercially available surface treatments of NC, GN, FBN, and PN.

\section{Materials and methods}

\subsection{Surface treatments}

Impax Supreme (equivalent to AISI P20) premium pre-hardened plastic mould steel (ASSAB, Turkey) having a chemical composition (in wt) of $0.334 \%$ C, $0.234 \% \mathrm{Si}, 1.35 \% \mathrm{Mn}, 1.92 \% \mathrm{Cr}, 0.913 \% \mathrm{Ni}, 0.229 \%$ Mo, $0.017 \% \mathrm{~S}$, and balanced by Fe was used as a base material having $25 \times 10 \times 30 \mathrm{~mm}$ dimensions. The chemical composition was also examined by EDS analysis as an average of four measurements and the results were obtained as (in wt) $2,83 \pm 0,69 \% \mathrm{C}, 0,74 \pm 0,17 \% \mathrm{Si}$, $1,62 \pm 0,02 \% \quad \mathrm{Mn}, \quad 2,11 \pm 0,14 \% \quad \mathrm{Cr}, \quad 0,98 \pm 0,20 \% \quad \mathrm{Ni}$, $1,47 \pm 0,62 \% \mathrm{Mo}$, and $90,25 \pm 1,72 \% \mathrm{Fe}$. Surface treatments were performed in industrial gas-nitriding, fluidized-bed, vacuum, and nitrocarburizing furnaces. Gas mixture of $45 \% \mathrm{CO}_{2}+29 \% \mathrm{NH}_{3}+26 \%$ $\mathrm{N}_{2}$ was used for $\mathrm{NC}, 94 \% \mathrm{NH}_{3}+6 \% \mathrm{~N}_{2} \mathrm{O}, 90 \% \mathrm{NH}_{3}+5 \% \mathrm{~N}_{2} \mathrm{O}+5 \%$ $\mathrm{N}_{2}$ and $89 \% \mathrm{NH}_{3}+9 \% \mathrm{~N}_{2}+2 \% \mathrm{~N}_{2} \mathrm{O}$ was used for GN, $60 \% \mathrm{~N}_{2}+40 \%$ $\mathrm{NH}_{3}$ was used for FBN, and finally $25 \% \mathrm{~N}_{2}+75 \% \mathrm{H}_{2}$ was used for PN.
Nitriding process was performed at $560^{\circ} \mathrm{C}$ during $8 \mathrm{~h}$ for NC, GN, and FBN, while it was performed at $520^{\circ} \mathrm{C}$ during $8 \mathrm{~h}$ for PN. More details on the processing methodology were given elsewhere [22].

\subsection{Corrosion and tribocorrosion tests}

Prior to the corrosion tests, UT samples were grinded using SiC papers and polished up to $3 \mu \mathrm{m}$ grain size using a diamond suspension, and kept in the desiccator for $24 \mathrm{~h}$ whereas nitrided and nitrocarburized samples were tested in as-treated surface conditions. Corrosion tests were carried out in $3.5 \mathrm{wt} \% \mathrm{NaCl}$ solution at room temperature, using a Reference 600 potentiostat/galvanostat from Gamry Instruments. Testing samples placed in a conventional three-electrode electrochemical cell (adapted from ASTM: G3-89) with an exposed area of $0.38 \mathrm{~cm}^{2}$ were used as working electrode, saturated calomel electrode (SCE) was used as reference electrode, and a Pt wire was used as counter electrode. Prior to electrochemical impedance spectroscopy (EIS), open circuit potential (OCP) was measured during $60 \mathrm{~min}$. The impedance data acquisition was performed by scanning a range of frequencies from $63 \mathrm{kHz}$ till $10 \mathrm{MHz}$, with 10 points per frequency decade. The amplitude of the sinusoidal signal was $10 \mathrm{mV}$ in order to assure the linearity of the electrode response. Finally, the potentiodynamic polarization measurements were performed starting from $0.25 \mathrm{~V}$ below the $\mathrm{E}_{\mathrm{OCP}}$ up to the anodic domain $(0 \mathrm{~V})$ with a scan rate of $0.5 \mathrm{mV} / \mathrm{s}$.

Tribocorrosion tests were performed under OCP, with the same surface conditions, temperature, electrolyte, three-electrode set-up, and potentiostat as the corrosion tests, using a ball-on-plate tribometer (CETR-UMT-2). After reaching the stable OCP values, the normal load $(15 \mathrm{~N})$ was applied and the sliding started against the counter material (10 $\mathrm{mm}$ diameter alumina ball, Goodfellow) in a reciprocating system with a total stroke length of $5 \mathrm{~mm}$, frequency of $1 \mathrm{~Hz}$, and total sliding time of $20 \mathrm{~min}$.

All corrosion and tribocorrosion tests were repeated at least three times in order to have repeatability, and the experimental results are presented as the average \pm standard deviation.

\subsection{Characterization}

Cross-sections of the nitrided samples were prepared by using SiC papers and diamond suspension down to $3 \mu \mathrm{m}$ grain size. The microstructures were characterized using backscattered (BSE) and secondary electron (SE) detector signals under FEI Nova 200 Field Emission Gun Scanning Electron Microscope (FEG-SEM) equipped with EDAX, Energy Dispersive X-Ray Spectroscopy (EDS). Phases formed on the base steel and the treated surfaces were characterized by X-ray diffractometer $(\mathrm{Cu}$ $\mathrm{K} \alpha$ radiation, Bruker D8 Discover). After corrosion and the tribocorrosion tests, samples were ultrasonically cleaned in propanol for $10 \mathrm{~min}$ followed by distilled water for $5 \mathrm{~min}$. The tested surfaces were also characterized by using FEG-SEM/EDS.

\section{Results and discussion}

\subsection{As-treated surfaces}

Two surface layers, namely the compound layer and the diffusion layer for each nitrided sample can be seen on the cross-sectional BSE SEM images given in Fig. 1. Thickness of the compound layers obtained by image analysis methods were given elsewhere [22] as $11.55 \pm 1.79,9.27 \pm 1.29,14.33 \pm 1.32$, and $5.49 \pm 1.39 \mu \mathrm{m}$ for NC, GN, FBN, and PN, respectively. All nitrided samples presented similar surface micro-hardness values obtained under load of $1 \mathrm{~kg}$ for 15 s, being $888 \pm 33,895 \pm 62,851 \pm 83,886 \pm 100 \mathrm{HV}_{1}$ for NC, GN, FBN, and PN, respectively, that was substantially higher than that of the untreated sample $\left(352 \pm 11 \mathrm{HV}_{1}\right)$ [22]. On the other hand, it was observed from the hardness profiles that was given elsewhere [22] 

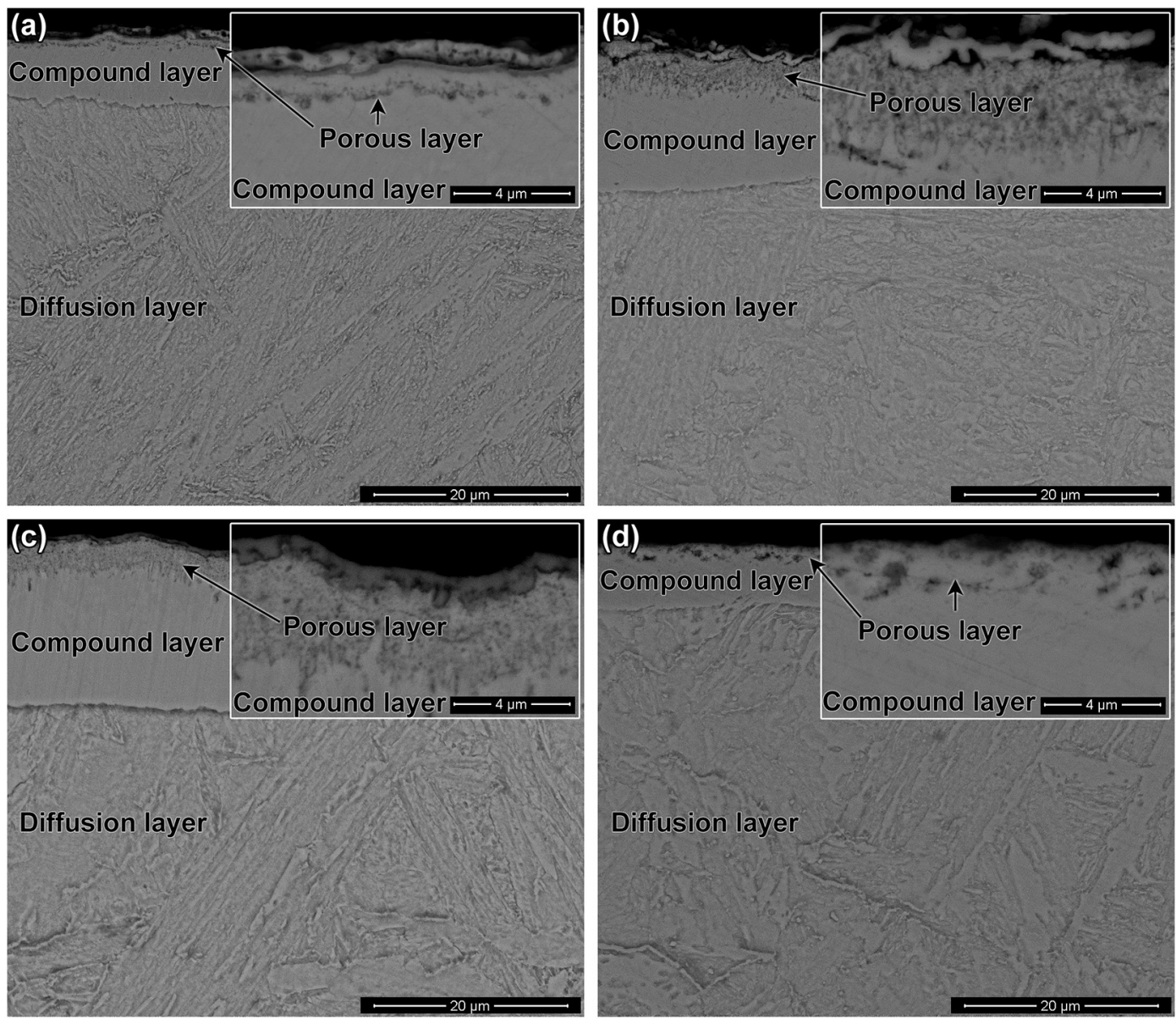

Fig. 1. BSE SEM images of the cross-section of a) NC, b) GN, c) FBN, and d) PN samples.

that PN presented the largest case depth which is known as more effective and uniform as compared to the other nitriding methods [2,26].

It was also observed from cross-sectional SEM images that the outmost part of the compound layers presented porosity. It is known that during processing, high nitrogen pressure in the compound layer leads to the precipitation of molecular nitrogen results in formation of a porous structure in the compound layer [27,28]. No methodological studies were performed in order to quantify the volume fraction of porosity; however, it was measured on the cross-sectional SEM images that GN and FBN resulted in deeper porous layers as compared to NC and $\mathrm{PN}$, having values of $4.72 \pm 0.27,3.92 \pm 0.26,1.70 \pm 0.05$, and $1.63 \pm 0.25 \mu \mathrm{m}$, respectively.

$\mathrm{XRD}$ analysis of the untreated and treated surfaces were given in the previous study [22] where the untreated surface presented only $\alpha$-Fe phase and treated samples presented $\varepsilon-\mathrm{Fe}_{2-3} \mathrm{~N}$ and $\gamma^{\prime}-\mathrm{Fe}_{4} \mathrm{~N}$ that is in accordance with the literature where these compounds have been reported as the main constituents of the compound layer after nitriding processes [26,29-33]. Besides, NC and FBN samples presented 3 and $4 \%$ of $\mathrm{Fe}_{2} \mathrm{O}_{3}$ phase, respectively, that may be due to the residual air in the furnace during the process $[22,26,34]$. The phase percentages in the treated samples were calculated based on the XRD spectra given in the previous study [22] by following Eq. (1), and the results are given in Table 1.

$\%$ phase $e_{\alpha}=\frac{\sum \mathrm{I}_{\alpha \text { peaks }}}{\sum \mathrm{I}_{\text {all peaks }}} \times 100$

\subsection{Corrosion behaviour}

The potentiodynamic polarization curves of the untreated and
Table 1

Phase percentages in the treated samples.

\begin{tabular}{lllll}
\hline \multirow{2}{*}{ Phase } & \multicolumn{2}{l}{ Phase percentage } & & \\
\cline { 2 - 5 } & $\mathrm{NC}$ & $\mathrm{GN}$ & FBN & PN \\
\hline$\varepsilon-\mathrm{Fe}_{3} \mathrm{~N}$ & 49 & 48 & 40 & 51 \\
$\gamma-\mathrm{Fe}_{4} \mathrm{~N}$ & 48 & 52 & 56 & 49 \\
$\mathrm{Fe}_{2} \mathrm{O}_{3}$ & 3 & - & 4 & - \\
\hline
\end{tabular}

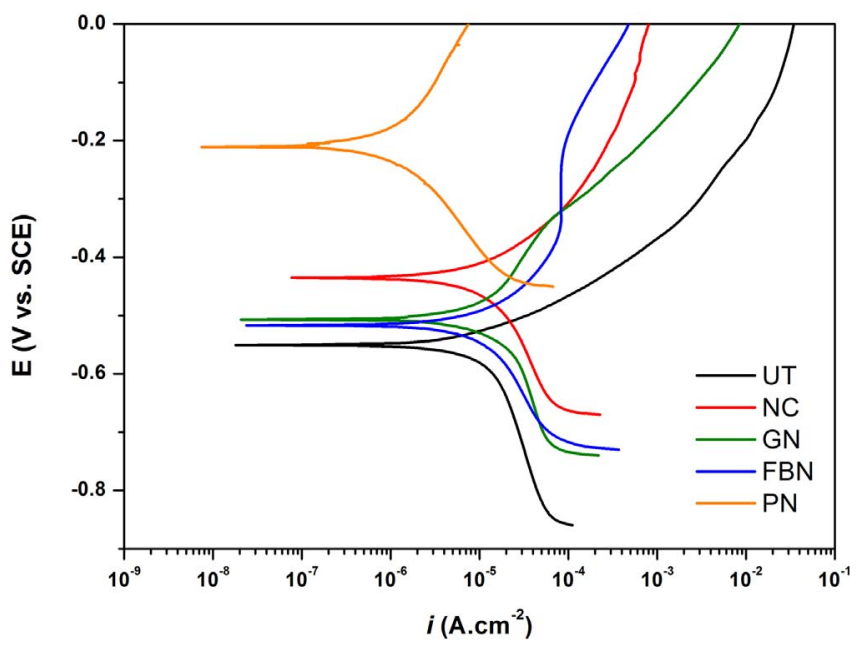

Fig. 2. Potentiodynamic polarization curves. 
Table 2

Corrosion potential $\left(\mathrm{E}_{(i=0)}\right)$ and corrosion current density $\left(i_{\text {corr }}\right)$ for all tested samples.

\begin{tabular}{lll}
\hline & $\mathrm{E}_{(i=0)}(\mathrm{mV})$ & $i_{\text {corr }}\left(\mu \mathrm{A} \cdot \mathrm{cm}^{-2}\right)$ \\
\hline UT & $-561 \pm 12$ & $18.10 \pm 6.01$ \\
NC & $-478 \pm 38$ & $6.76 \pm 0.70$ \\
GN & $-529 \pm 23$ & $7.30 \pm 1.81$ \\
FBN & $-448 \pm 130$ & $4.23 \pm 1.35$ \\
PN & $-237 \pm 22$ & $0.50 \pm 0.17$ \\
\hline
\end{tabular}

treated samples in $3.5 \mathrm{wt} \% \mathrm{NaCl}$ solution are given Fig. 2. Corrosion current density $\left(i_{\text {corr }}\right)$ values were determined with Tafel extrapolation by considering a linear region of $20 \mathrm{mV}$ for all samples, and the results are listed in Table 2, together with corrosion potential $\left(\mathrm{E}_{(i=0)}\right)$ values. As compared to UT samples, the potentiodynamic polarization curves were shifted to the upper-left, being more distinguishable on the PN samples. $\mathrm{E}_{(i=0)}$ values became more negative and $i_{\text {corr }}$ values were increased in the order of UT, GN, NC, FBN, and PN, pointing that lowest tendency to corrosion and lowest corrosion rates were obtained on PN samples.

The diffusion layer consists of very fine nitride particles where the nitrogen content decreases towards the core [35]. Also, as referred above, compound layer consists of iron nitrides, the epsilon phase $(\varepsilon$ $\left.\mathrm{Fe}_{2-3} \mathrm{~N}\right)$ and/or the gamma phase $\left(\gamma^{\prime}-\mathrm{Fe}_{4} \mathrm{~N}\right)[2,3,9,13,14]$. Nitrides such as $\varepsilon$ and $\gamma^{\prime}$ are noble phases and they are more positive with respect to steel in the electrochemical series. Hence, they provide protection while remaining intact. Therefore, after nitriding and nitrocarburizing, the corrosion resistance is expected to increase due to the formation of iron nitride phases on the surface [28]. However, it is known that the defects on the compound layer can decrease the corrosion resistance of the nitrided steels, by originating galvanic coupling [3]. Thus, relatively thicker but porous layers on the GN, FBN, and NC samples may lead to obtain higher $i_{\text {corr }}$ values as compared to PN samples.

Fig. 3 presents the EIS spectra in the form of Bode diagram. PN samples presented the highest values of the impedance modulus $(|\mathrm{Z}|)$, followed by NC, GN, FBN, and UT samples in a decreasing order, pointing that the highest polarization resistance was given by PN samples (Fig. 3a). Regarding the phase angle values (Fig. 3b), PN samples exhibited the highest values approaching to $-70^{\circ}$, together with a larger plateau on the middle and low frequencies, indicating a best protective character of both, compound layer and the diffusion layer, when compared with NC, GN and FBN samples. NC, GN, and UT samples presented similar maximum phase angle values, however, NC samples exhibited a larger plateau on frequencies between 10 and (a)

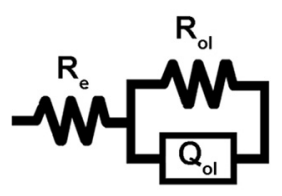

(b)

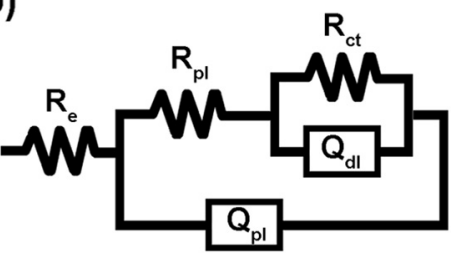

UT, PN

Fig. 4. EECs used for a) UT and PN, b) GN, FBN, and NC.

$10^{-1} \mathrm{~Hz}$. The main difference between GN and UT samples was on the frequency range where the phase angle exhibited the highest value $\left(-64^{\circ}\right)$, namely $0.25 \mathrm{~Hz}$ and $4.86 \mathrm{~Hz}$ for GN and UT, respectively. NC, $\mathrm{GN}$, and FBN samples presented two time constants but it was more evident on FBN samples, where the first time constant was obtained close to $-35^{\circ}$ and the second one was close to $-45^{\circ}$.

The impedance spectra were fitted to the corresponding electrochemical equivalent circuits (EECs) using ZView software (version 2.9). A constant phase element (CPE) was used for the fitting considering the deviation from an ideal capacitor behaviour [36]. The quality of fitting was evaluated through their $\chi^{2}$ values and the proposed models described sufficiently the behaviour of both groups with $\chi^{2}$ values bellow $10^{-3}$.

The EECs used to fit the EIS data are given in Fig. 4. In the case of UT and PN samples, the EEC is the modified Randles' circuit with an electrolyte resistance, $R_{e}$, resistance of the outmost layer, $R_{o l}$ (discontinuous oxide film for UT and compound layer for PN), and CPE, $\mathrm{Q}_{\mathrm{ol}}$, considering a non-ideal capacitance of the outmost layer. However, this EEC was not able to represent GN, NC, and FBN samples, where a thicker compound layer containing higher amount of visible porosity was observed. Thus, the components of the EEC selected for GN, NC, and FBN samples are electrolyte resistance, $R_{e}$, and the loop $R_{p l} / Q_{p l}$ representing the resistance and the capacitance of the porous layers. The contribution of the process taking place at the interface between the dense part of the compound layer and electrolyte is represented by $\mathrm{R}_{\mathrm{ct}} / \mathrm{Q}_{\mathrm{dl}}$. The charge transfer reaction is represented by $\mathrm{R}_{\mathrm{ct}}$ while $\mathrm{Q}_{\mathrm{dl}}$ stands for the capacitance (CPE) of the double layer effect.

EEC parameters obtained from EIS data for UT and PN are given in Table 3. Regarding the resistance of the outmost layer, UT samples presented much lower resistance as compared to PN samples. The similar $\mathrm{Q}_{\mathrm{ol}}$ values may be explained by the roughness and the heterogeneities that were present in both cases which were also noticeable on
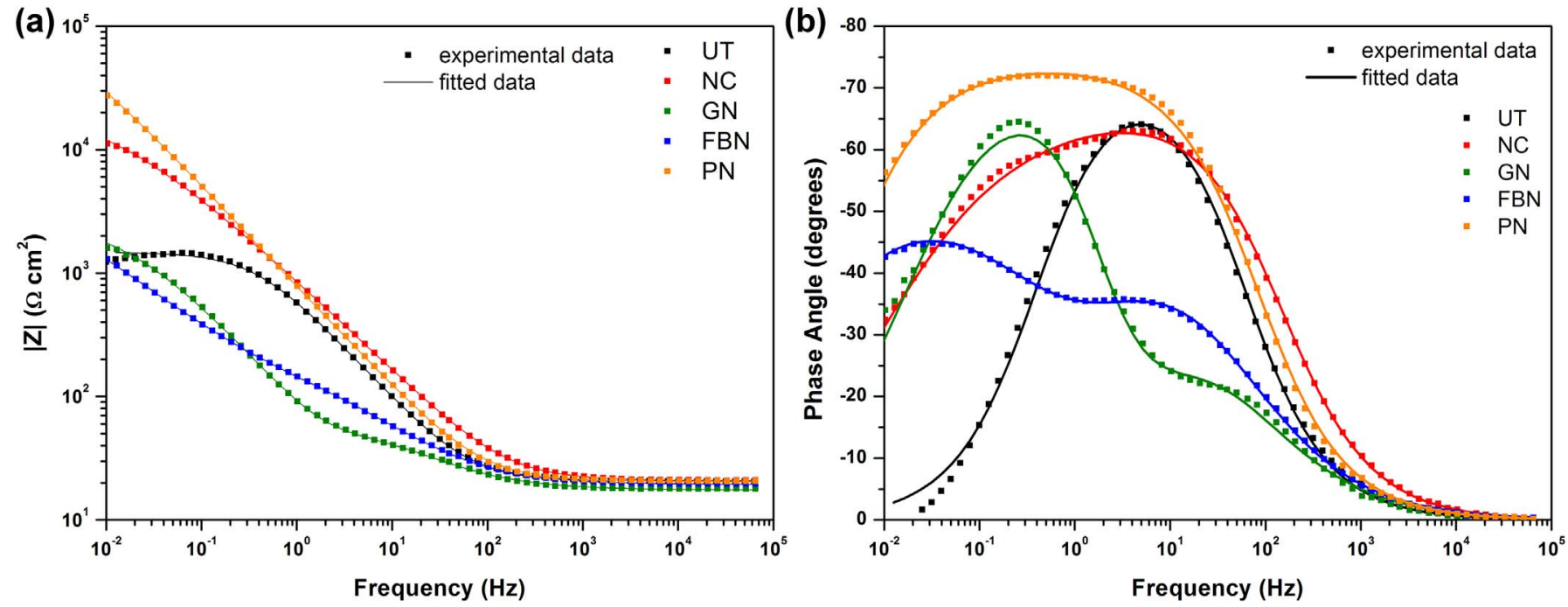

Fig. 3. EIS spectra in the form of Bode diagram; a) $|\mathrm{Z}|$ and b) phase angle. 
Table 3

Equivalent circuit parameters obtained from EIS data for UT and PN.

\begin{tabular}{lll}
\hline & UT & PN \\
\hline $\mathrm{R}_{\mathrm{ol}}\left(\Omega \mathrm{cm}^{2}\right)$ & $1395 \pm 150$ & $57,767 \pm 25,751$ \\
$\mathrm{Q}_{\mathrm{ol}}\left(\times 10^{-4} \mathrm{~s}^{\mathrm{n}} \Omega^{-1} \mathrm{~cm}^{-2}\right)$ & $3.02 \pm 0.09$ & $3.06 \pm 0.24$ \\
$\mathrm{n}_{\mathrm{ol}}$ & $0.851 \pm 0.003$ & $0.825 \pm 0.003$ \\
\hline
\end{tabular}

the $\mathrm{n}_{\mathrm{ol}}$ values. It is known that roughness and heterogeneities leads to the non-uniform distribution of current and it affects the $n$ values [37]. Before the electrochemical tests, UT and PN samples presented different surface roughness $\left(R_{a}\right)$ values as $0.12 \pm 0.06$ and $0.20 \pm 0.05 \mu \mathrm{m}$, respectively (measured by Mahr SP5 contact profilometer). On the other hand, it was observed on the SEM image and the corresponding EDS analysis of the corroded UT sample surfaces that corrosion products (i.e. oxides) formed a discontinuous/heterogeneous layer, probably not well-adherent to the surface (Fig. 5), which may also explain why highest values of phase angle were obtained at relatively lower frequencies on UT samples.

EEC parameters obtained from EIS data for GN, FBN, and NC are given in Table 4. Regarding the CPE of the outmost porous layer (i.e. compound layer), NC samples exhibited the lowest values, whereas GN and FBN samples presented similar values. Independently of the nitriding treatment, $\mathrm{R}_{\mathrm{pl}}$ presented relatively low values. Arenas and Damborenea [38] reported similar behaviour for commercially galvanised steel. The authors attributed this behaviour to the extremely porous oxide layers which affected the layer resistance. Moreover, the authors stated that this surface morphology led to a heterogeneous signal distribution on the metal surface. Regarding $\mathrm{R}_{\mathrm{ct}}$, GN presented significantly higher values than NC and FBN, where NC presented the lowest values. On the other hand, when CPE of the double layer was considered, lowest values were obtained on GN whereas highest values were given by FBN samples. It is known that $R_{c t}$ is affected by the size and depth of the pores whereas CPE of the double layer is affected by the roughness and the heterogeneities on the pore sites [39]. As also discussed above, GN and FBN presented thicker porous zone in the compound layer as compared to the other nitrided surfaces. When GN and FBN compared, GN samples seems to have bigger pores as compared to the FBN samples, as observed in Fig. 1. Besides, the higher values of $\mathrm{R}_{\mathrm{ct}}$ in the case of $\mathrm{GN}$ are in accordance with the potentiodynamic polarization curves, where higher current densities were observed in the anodic domain. Moreover, GN and FBN samples presented lower $\mathrm{n}_{\mathrm{dl}}$ as compared to the NC.

\subsection{Tribocorrosion behaviour}

The evolution of OCP before, during and after sliding for the untreated and treated samples is given in Fig. 6, together with the evolution of COF during sliding. Before sliding, OCP values were stable for all samples. When sliding started, two behaviours were observed: OCP values of PN and NC decreased to more negative values while the values of UT, GN, and FBN increased. After sliding, the potential values approached values near to the initial ones, except for the FBN sample where the values were kept on increasing after sliding.

On the evolution of OCP for UT samples, a sudden increase was observed on the onset of the sliding, followed by relatively stable values during sliding. After sliding, the values decreased rapidly near the initial values. On the other hand, after a sudden increase, COF values were decreased during approx. first $200 \mathrm{~s}$ then proceeded relatively stable till the end of the sliding. On the previous study of the present authors where dry sliding behaviour of the same materials investigated [22], two stages were reported: (i) a run-in period where the main wear mechanism was a combination of adhesive and abrasive wear which caused large oscillations on the COF values due to stick-slip phenomena together with the third body effect of the detached material, and a steady-state period (mild wear) that was mainly oxidative wear. In tribocorrosion conditions, large oscillations were not observed on the first stage of sliding and the transition to the steady-state was relatively smoother. This can be explained by the presence of the aqueous solution that can decrease the adhesive wear by acting as a lubricant and can remove some of the third-body particles from the wear zone resulting with reduced third-body action under sliding. Decrease on the COF values on the other hand, can be explained by the formation of a compacted layer of oxide debris and corrosion products on the sliding surface that can also explain the increased OCP values during sliding. Compacted layer of wear debris and corrosion products can be seen clearly on the detailed SEM images of the worn surface (Fig. 7). After sliding, OCP values were rapidly decreased near the initial values and remained relatively stable till the end of the immersion time. Rapid decrease on the OCP values after sliding can be explained by the liberation of some of the oxide degradation products on the absence of the packing effect of the counter material.

Increased OCP values under tribocorrosion due to the formation of o compacted protective film from wear products were also reported before for different metal-based surfaces $[40,41]$. Accordingly, similar to the UT sample, FBN and GN samples also presented higher potential values under sliding as compared to the stabilization period. This behaviour may be related to the deeper outmost porous layer on these samples. During sliding, the wear debris can be accumulated on the pores and by the effect of the counter material, it can be resulted with
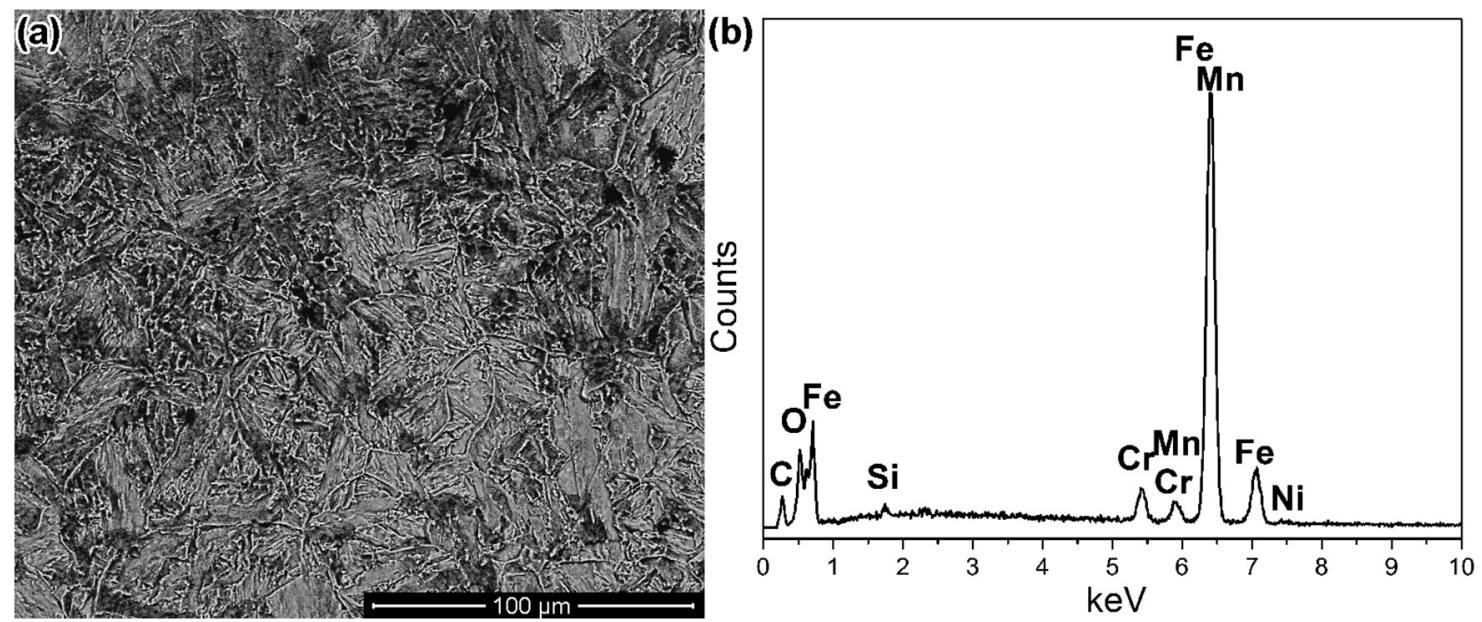

Fig. 5. a) BSE SEM image and b) the corresponding EDS spectrum of the corroded UT sample. 
Table 4

Equivalent circuit parameters obtained from EIS data for GN, FBN, and NC.

\begin{tabular}{lll}
\hline & GN & FBN \\
\hline $\mathrm{R}_{\mathrm{pl}}\left(\Omega \mathrm{cm}^{2}\right)$ & $37 \pm 16$ & $48 \pm 18$ \\
$\mathrm{Q}_{\mathrm{pl}}\left(\times 10^{-4} \mathrm{~s}^{\mathrm{n}} \Omega^{-1} \mathrm{~cm}^{-2}\right)$ & $0.16 \pm 0.01$ & $0.14 \pm 0.05$ \\
$\mathrm{n}_{\mathrm{pl}}$ & $0.701 \pm 0.032$ & $0.656 \pm 0.028$ \\
$\mathrm{R}_{\mathrm{ct}}\left(\Omega \mathrm{cm}^{2}\right)$ & $2378 \pm 271$ & $5455 \pm 413$ \\
$\mathrm{Q}_{\mathrm{dl}}\left(\times 10^{-4} \mathrm{~s}^{\mathrm{n}} \Omega^{-1} \mathrm{~cm}^{-2}\right)$ & $7.88 \pm 3.84$ & $0.47 \pm 2.36$ \\
$\mathrm{n}_{\mathrm{dl}}$ & $0.680 \pm 0.010$ & $0.667 \pm 0.113$ \\
\hline
\end{tabular}

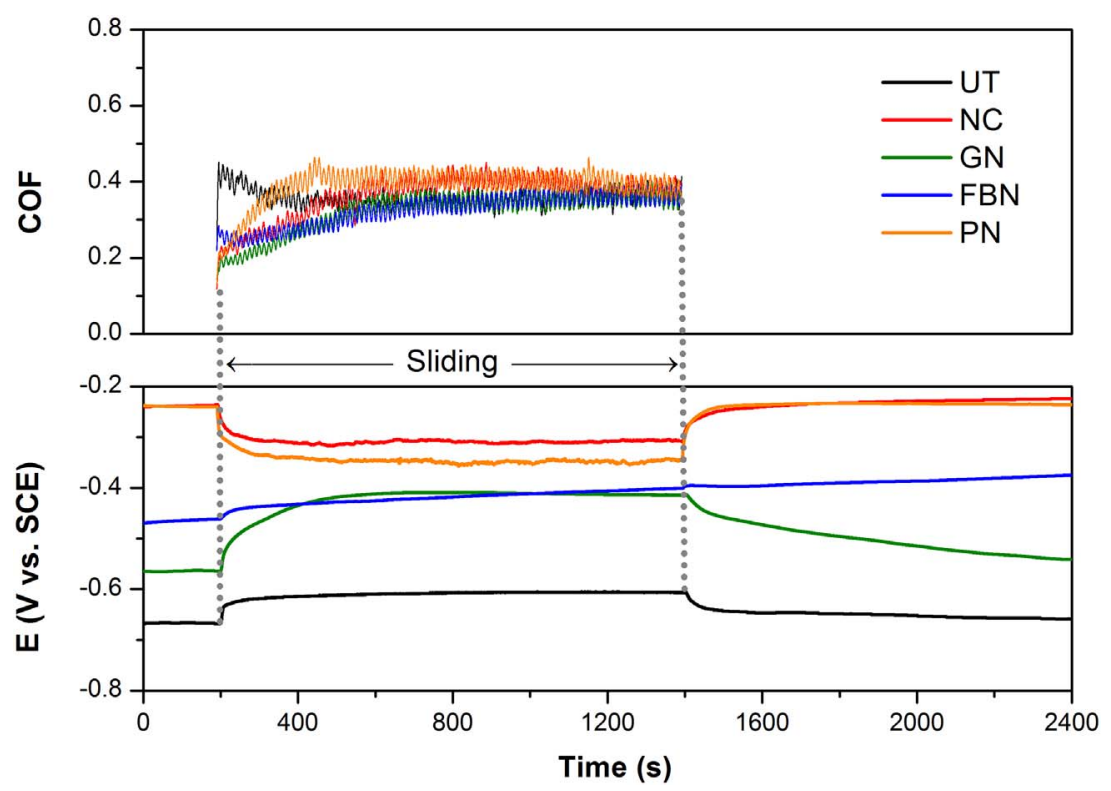

Fig. 6. Evolution of OCP together with COF values during sliding.

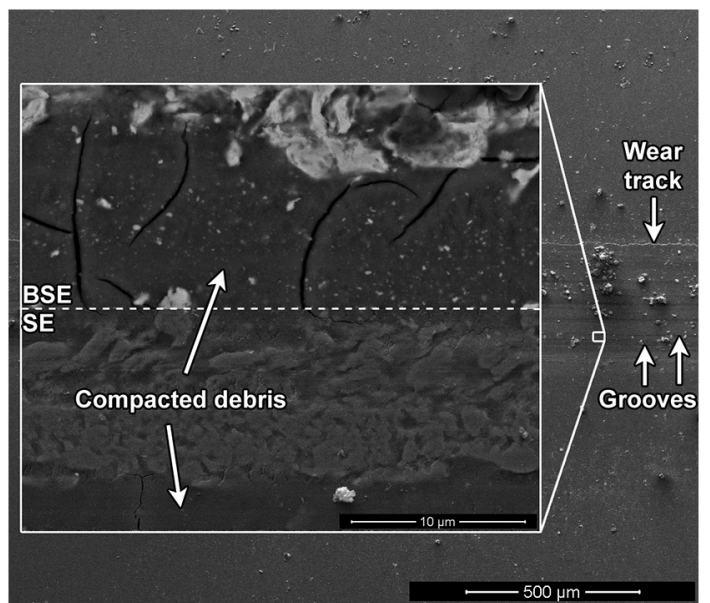

Fig. 7. SEM images of worn UT surface.

closure of the pores that make it harder for the electrolyte to penetrate through the compound layer. This may be related with the relatively bigger pores on the compound layer of GN samples (Fig. 1b) as compared to FBN samples (Fig. 1c). Thus, a bigger influence on the potential might be explained by the closure of larger porous region on GN samples. Accordingly, after sliding, packed wear debris may be released relatively easier from the bigger pores of GN samples that might explain the decrease on the potential values after sliding. On the other hand, when sliding started, NC and PN samples presented a cathodic shift, having values around 0.074 and $0.107 \mathrm{~V}$, respectively. It is known that iron nitride is passivatable [23], thus, the cathodic shift observed on NC and PN can be related to depassivation due to the sliding action.
Nevertheless, it is clear that further triboelectrochemical studies and sub-surface analysis of the worn surfaces are necessary to have a better understanding on the tribocorrosion mechanism of the nitrided surfaces.

The COF values under sliding presented similar trends for all nitrided samples where a gradually increase was observed during approx. first $300 \mathrm{~s}$ of sliding and after that the values proceeded relatively stable till the end of the sliding. However, the increase on the values was relatively faster on the PN and NC samples, followed by slightly higher values during sliding. Nevertheless, at the end of the sliding, COF values were very similar in all samples. This small difference on the evolution of COF values for the nitrided samples may also be attributed to the porous outmost layer where higher amount of porosity can facilitate the packing of the wear products on the surfaces thus reducing the thirdbody effect and therefore lowering the COF values for GN and FBN samples.

Fig. 8 presents the SEM images of the worn surfaces the nitrided samples. Parallel abrasion scratches and compacted wear debris were visible on all worn surfaces. As a first approach to the comparison of the tribocorrosion behaviour of the nitrided and nitrocarburized steels, the focus was given on the first contact without totally removing the white layer. Thus, due to the chosen tribological parameters, the machining marks were still visible on the wear tracks. On the other hand, since the material removal after tribocorrosion tests were relatively lower, no methodological study was performed on quantification of the material loss after testing. Even though, it can be seen on the SEM images of the wear tracks that the PN sample presented the narrower width as compared to the other samples.

\section{Conclusions}

Within the framework and limitations of this study, it can be 

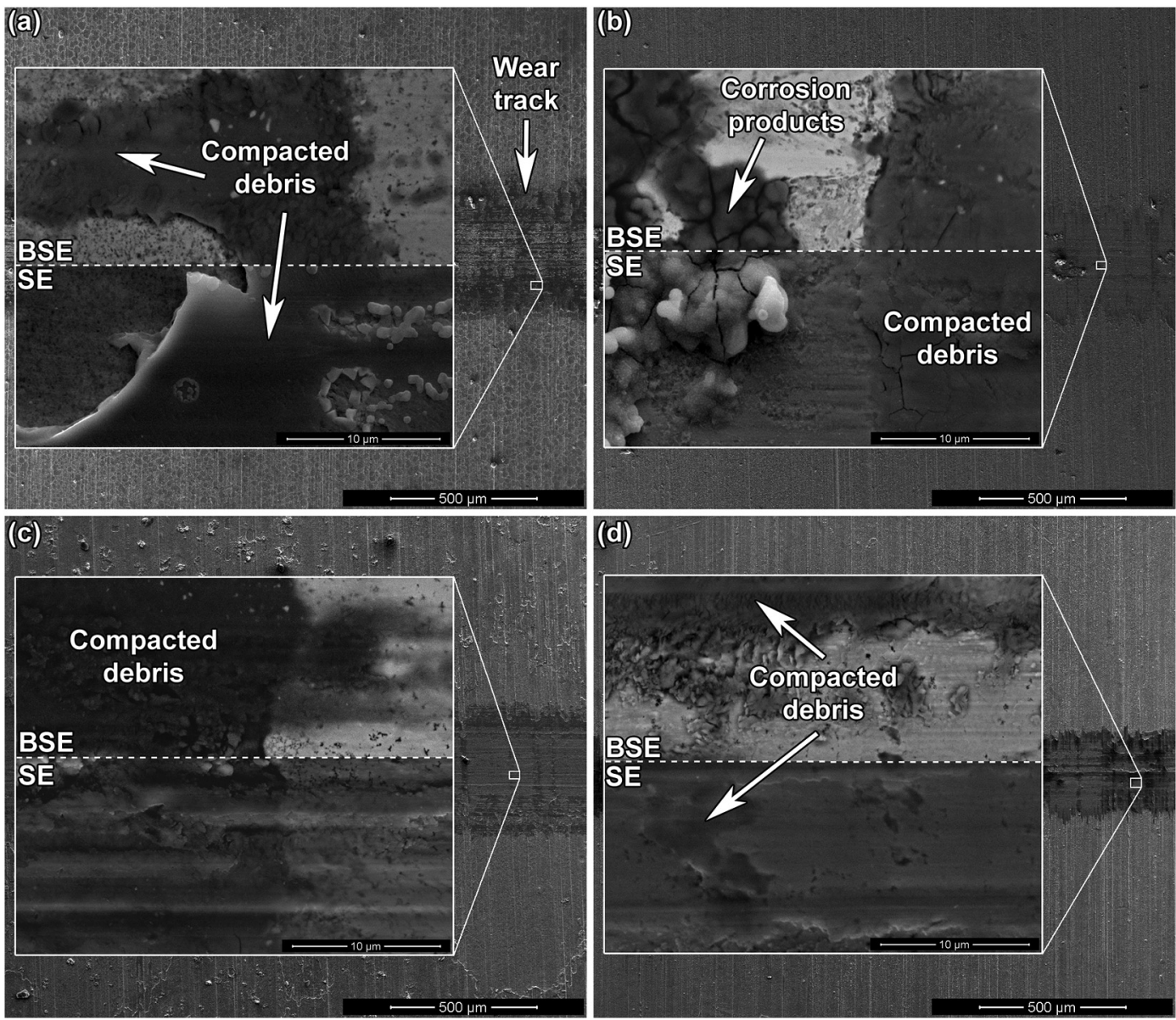

Fig. 8. SEM images of worn a) NC, b) GN, c) FBN, and d) PN surfaces.

concluded that PN treatment provides better corrosion behaviour in terms of tendency to corrosion, corrosion rate, and polarization resistance, as compared to the other studied surface treatments (NC, GN, and FBN), probably due to formation of a denser compound layer. Under both corrosion and tribocorrosion conditions, PN and NC treated surfaces exhibited lower tendency to corrosion, that also seems to be affected by the porosity of the compound layer, that was thicker on GN and FBN treated surfaces.

\section{Acknowledgements}

This study was supported by YULAP under Project No. 2012-07-02YL04 (Turkey), Centre for Mechanical and Materials Technologies (CT2M) in Portugal, and The Calouste Gulbenkian Foundation through 'Programa de Mobilidade Académica para Professores', and FCT with the reference project UID/EEA/04436/2013, by FEDER funds through the COMPETE 2020 - Programa Operacional Competitividade e Internacionalização (POCI) with the reference project POCI-01-0145FEDER-006941. The authors gratefully acknowledge ASSAB Çelik ve Isil Islem AS and Istanbul Isil Islem San. ve Tic. AS and Quantum Takim Sanayi Urunleri Çelik ve Tic. AS for their kind help on the nitriding processes.

\section{References}

1] F. Rosalbino, G. Scavino, G. Mortarino, Electrochemical corrosion behaviour of innovative mould steels in a chloride-containing environment, Mater. Corros. 63 (2012) 105-110, http://dx.doi.org/10.1002/maco.201005794.

[2] D. Wen, Plasma nitriding of plastic mold steel to increase wear- and corrosion properties, Surf. Coat. Technol. 204 (2009) 511-519, http://dx.doi.org/10.1016/j. surfcoat.2009.08.023.
[3] P. Novák, D. Vojtech, J. Serak, Wear and corrosion resistance of a plasma-nitrided PM tool steel alloyed with niobium, Surf. Coat. Technol. 200 (2006) 5229-5236, http://dx.doi.org/10.1016/j.surfcoat.2005.06.023.

[4] P. Hubbard, J.G. Partridge, E.D. Doyle, D.G. Mcculloch, M.B. Taylor, S.J. Dowey, Investigation of nitrogen mass transfer within an industrial plasma nitriding system I: the role of surface deposits, Surf. Coat. Technol. 204 (2010) 1145-1150, http:// dx.doi.org/10.1016/j.surfcoat.2009.08.029.

[5] C.H. Knerr, T.C. Rose, J.H. Filkowski, Gas nitriding of steels, ASM Handbook, vol. 4 ASM International, 1991.

[6] D. Pye, Practical Nitriding and Ferritic Nitrocarburizing, ASM International (2003),

[7] M. Berg, C.V. Budtz-Jørgensen, H. Reitz, K.O. Schweitz, J. Chevallier, P. Kringhøj, J. Bøttiger, On plasma nitriding of steels, Surf. Coat. Technol. 124 (2000) 25-31, http://dx.doi.org/10.1016/S0257-8972(99)00472-7.

[8] E.V. Pereloma, A.W. Conn, R.W. Reynoldson, Comparison of ferritic nitrocarburising technologies, Surf. Coat. Technol. 145 (2001) 44-50, http://dx.doi.org/10. 1016/S0257-8972(01)01308-1.

[9] S.S. Akhtar, A.F.M. Arif, B.S. Yilbas, Evaluation of gas nitriding process with inprocess variation of nitriding potential for AISI H13 tool steel, Int. J. Adv. Manuf. Technol. 47 (2010) 687-698, http://dx.doi.org/10.1007/s00170-009-2215-4.

[10] B. Podgornik, J. Vizintin, V. Leskovsek, Tribological properties of plasma and pulse plasma nitrided AISI 4140 steel, Surf. Coat. Technol. 108-109 (1998) 454-460.

[11] N. Nayebpashaee, H. Vafaeenezhad, S. Kheirandish, M. Soltanieh, Experimental and numerical study on plasma nitriding of AISI P20 mold steel, Int. J. Miner. Metall. Mater. 23 (2016) 1065-1075, http://dx.doi.org/10.1007/s12613-016-1324-y.

[12] K.S. Al-Rubaie, F. Steinmeier, M. Pohl, Two-body abrasion of nitrocarburised steels for hydraulic cylinders, Wear 243 (2000) 112-121, http://dx.doi.org/10.1016/ S0043-1648(00)00424-5.

[13] A. Basu, J.D. Majumdar, J. Alphonsa, S. Mukherjee, I. Manna, Corrosion resistance improvement of high carbon low alloy steel by plasma nitriding, Mater. Lett. 62 (2008) 3117-3120, http://dx.doi.org/10.1016/j.matlet.2008.02.001.

[14] D.C. Wen, Microstructure and corrosion resistance of the layers formed on the surface of precipitation hardenable plastic mold steel by plasma-nitriding, Appl. Surf. Sci. 256 (2009) 797-804, http://dx.doi.org/10.1016/j.apsusc.2009.08.062.

[15] O. Öztürk, O. Onmuş, D.L. Williamson, Microstructural, mechanical, and corrosion characterization of plasma-nitrided plastic injection mould steel, Surf. Coat. Technol. 196 (2005) 341-348, http://dx.doi.org/10.1016/j.surfcoat.2004.08.154.

[16] H. Hill, U. Raab, S. Weber, W. Theisen, M. Wollmann, L. Wagner, Influence of heat treatment on the performance characteristics of a plastic mold steel, Steel Res. Int. 82 (2011) 1290-1296, http://dx.doi.org/10.1002/srin.201100098. 
[17] J. Bergstrom, F. Thuvander, P. Devos, C. Boher, Wear of die materials in full scale plastic injection moulding of glass fibre reinforced polycarbonate, Wear 251 (2001) 1511-1521, http://dx.doi.org/10.1016/S0043-1648(01)00787-6.

[18] M.D. Bermúdez, P. Iglesias, A.E. Jiménez, G. Martínez-Nicolás, Influence of sliding frequency on reciprocating wear of mold steel with different microstructures, Wear 267 (2009) 1784-1790, http://dx.doi.org/10.1016/j.wear.2008.12.025.

[19] R.L. Liu, Y.J. Qiao, M.F. Yan, Y.D. Fu, Effects of rare earth elements on the characteristics of low temperature plasma nitrocarburized martensitic stainless steel, J. Mater. Sci. Technol. 28 (2012) 1046-1052, http://dx.doi.org/10.1016/S10050302(12)60171-6.

[20] J.C. Díaz-Guillén, G. Vargas-Gutiérrez, E.E. Granda-Gutiérrez, J.S. Zamarripa-Piña, S.I. Pérez-Aguilar, J. Candelas-Ramírez, L. Álvarez-Contreras, Surface properties of Fe4N compounds layer on AISI 4340 steel modified by pulsed plasma nitriding, J. Mater. Sci. Technol. 29 (2013) 287-290, http://dx.doi.org/10.1016/j.jmst.2013. 01.017.

[21] M. Ulutan, O.N. Celik, H. Gasan, U. Er, Effect of different surface treatment methods on the friction and wear behavior of AISI 4140 steel, J. Mater. Sci. Technol. 26 (2010) 251-257, http://dx.doi.org/10.1016/S1005-0302(10)60042-4.

[22] E. Boztepe, A.C. Alves, A. Ramalho, E. Ariza, L.A. Rocha, N. Cansever, F. Toptan, A comparative study on the dry sliding wear behaviour of nitrocarburised, gas nitrided, fluidised-bed nitrided, and plasma nitrided plastic mould steel, Int. J. Surf. Sci. Eng. 10 (2016) 468, http://dx.doi.org/10.1504/IJSURFSE.2016.079044.

[23] H.-J. Spies, Corrosion Behaviour of Nitrided, Nitrocarburised and Carburised Steels, Woodhead Publishing Limited, 2015, http://dx.doi.org/10.1533/9780857096524. 2.267 .

[24] M. Esfandiari, H. Dong, Improving the surface properties of A286 precipitationhardening stainless steel by low-temperature plasma nitriding, Surf. Coat. Technol. 201 (2007) 6189-6196, http://dx.doi.org/10.1016/j.surfcoat.2006.11.013.

[25] P. Jemmely, S. Mischler, D. Landolt, Tribocorrosion behaviour of Fe - $17 \mathrm{Cr}$ stainless steel in acid and alkaline solutions, Tribol. Int. 32 (1999) 295-303.

[26] M. Mirjani, A. Shafyei, F. Ashrafizadeh, Plasma and gaseous nitrocarburizing of C60W steel for tribological applications, Vacuum 83 (2009) 1043-1048, http://dx. doi.org/10.1016/j.vacuum.2008.12.004.

[27] H. Kato, T.S. Eyre, B. Ralph, Sliding wear characteristics of nitrided steels, Surf. Eng. 10 (1994) 65-74.

[28] M. Fattah, F. Mahboubi, Comparison of ferritic and austenitic plasma nitriding and nitrocarburizing behavior of AISI 4140 low alloy steel, Mater. Des. 31 (2010) 3915-3921, http://dx.doi.org/10.1016/j.matdes.2010.03.008.

[29] R.L.O. Basso, R.J. Candal, C.A. Figueroa, D. Wisnivesky, F. Alvarez, Influence of microstructure on the corrosion behavior of nitrocarburized AISI H13 tool steel obtained by pulsed DC plasma, Surf. Coat. Technol. 203 (2009) 1293-1297, http:// dx.doi.org/10.1016/j.surfcoat.2008.10.006.

[30] L.-H. Chiu, C.-H. Wu, H. Chang, Wear behavior of nitrocarburized JIS SKD61 tool steel, Wear 253 (2002) 778-786, http://dx.doi.org/10.1016/S0043-1648(02) 00115-1.

[31] Y.H. Qiang, S.R. Ge, Q.J. Xue, Microstructure and tribological behaviour of nitrocarburizing-quenching duplex treated steel, Tribol. Int. 32 (1999) 131-136, http://dx.doi.org/10.1016/S0301-679X(99)00024-9.

[32] Y.Y. Özbek, M. Durman, H. Akbulut, Wear behavior of AISI 8620 steel modified by a pulse-plasma technique, Tribol. Trans. 52 (2009) 213-222, http://dx.doi.org/10. 1080/10402000802369721.

[33] W. Yue, X. Gao, C. Wang, X. Li, S. Wang, J. Liu, Synergistic effects between plasmanitrided AISI 52100 steel and zinc dialkyldithiophosphate additive under boundary lubrication, Tribol. Trans. 55 (2012) 278-287, http://dx.doi.org/10.1080/ 10402004.2011.651771.

[34] E. Haruman, Y. Sun, H. Malik, A.G.E. Sutjipto, S. Mridha, K. Widi, Low temperature fluidized bed nitriding of austenitic stainless steel, Solid State Phenom. 118 (2006) 125-130, http://dx.doi.org/10.4028/www.scientific.net/SSP.118.125.

[35] M.A. Pessin, M.D. Tier, T.R. Strohaecker, A. Bloyce, Y. Sun, T. Bell, The effects of plasma nitriding process parameters on the wear characteristics of AISI M2 tool steel, Tribol. Lett. 8 (2000) 223-228.

[36] N. Figueira, T.M. Silva, M.J. Carmezim, J.C.S. Fernandes, Corrosion behaviour of NiTi alloy, Electrochim. Acta 54 (2009) 921-926, http://dx.doi.org/10.1016/j. electacta.2008.08.001.

[37] W.R. Osório, M.V. Canté, C. Brito, E.S. Freitas, A. Garcia, Electrochemical behavior of an Al-Fe-Ni alloy affected by nano-sized intermetallic particles, Corrosion 71 (2015) 510-522, http://dx.doi.org/10.5006/1356.

[38] M.A. Arenas, Use of electrochemical impedance spectroscopy to study corrosion of galvanised steel in 0.6M NaCl solution, Corros. Eng. Sci. Technol. 41 (2006) $228-234$.

[39] M.E. Orazem, B. Tribollet, Electrochemical Impedance Spectroscopy, John Wiley \& Sons, New Jersey, 2008.

[40] J.R. Gomes, A.R. Ribeiro, A.C. Vieira, A.S. Miranda, L.A. Rocha, Wear mechanisms in functionally graded aluminium matrix composites: effect of the lubrication by an aqueous solution, Mater. Sci. Forum 492-493 (2005) 33-38.

[41] F. Toptan, A.C. Alves, I. Kerti, E. Ariza, L.A. Rocha, Corrosion and tribocorrosion behaviour of Al-Si-Cu-Mg alloy and its composites reinforced with B4C particles in $0.05 \mathrm{M} \mathrm{NaCl}$ solution, Wear 306 (2013) 27-35, http://dx.doi.org/10.1016/j.wear. 2013.06.026. 